\title{
Tear Proteomics in Young Malays with Dry Eyes
}

Mohd Ali Ba, Nguan DKCa, Bashirah Ia, Chan KM

\author{
a Optometry and Vision Science Program, Faculty of Health Sciences, Universiti Kebangsaan Malaysia, Jalan \\ Raja Muda Abdul Aziz, 50300 Kuala Lumpur Malaysia \\ ${ }^{b}$ Environmental Health and Industrial Safety Program, Faculty of Health Sciences, Universiti Kebangsaan \\ Malaysia, Jalan Raja Muda Abdul Aziz, 50300 Kuala Lumpur Malaysia
}

\section{ABSTRACT}

Introduction: Changes in tear protein concentrations may reflect ocular surface health. This study analyzes changes in tear protein concentrations of young Malays with dry eye (DE) and determines its association with the clinical findings. Methods: Subjects were screened using McMonnies questionnaire (MDEQ) and flourescein tear break up time (TBUT). Total tear protein concentration (TTPC) was determined using Bradford's technique and specific tear protein (slgA, lysozyme, lactoferrin and human serum albumin (HSA)) concentrations were determined using SDS-PAGE. Parametric and nonparametric tests were used to compare means between groups. Spearman correlation was used to determine the association between variables measured. Results: A total of 42 subjects ( $21 \mathrm{DE}$ and $21 \mathrm{NDE}$ ) were included. Mean MDEQ score for DE was $16.00 \pm 1.48$ and NDE was $8.47 \pm 3.47$. Mean TBUT for DE was $3.47 \pm 0.47 \mathrm{~s}$ and NDE was $4.98 \pm 0.43 \mathrm{~s}$. Mean TTPC for DE and NDE was $9.84 \pm 2.40 \mathrm{mg} / \mathrm{ml}$ and $8.96 \pm 1.84 \mathrm{mg} / \mathrm{ml}$ respectively. Mean slgA, lysozyme, lactoferrin and HSA for DE was $0.54 \pm 0.10 \mathrm{mg} / \mathrm{ml}, 1.68 \pm 0.17 \mathrm{mg} / \mathrm{ml}, 1.47 \pm 0.25 \mathrm{mg} / \mathrm{ml}, 0.06 \pm 0.03 \mathrm{mg} / \mathrm{ml}$ and for NDE was $0.57 \pm 0.09 \mathrm{mg} /$ $\mathrm{ml}, 2.04 \pm 0.19 \mathrm{mg} / \mathrm{ml}, 1.75 \pm 0.23 \mathrm{mg} / \mathrm{ml}, 0.06 \pm 0.03 \mathrm{mg} / \mathrm{ml}$ accordingly. Significant differences were noted in MDEQ score $(p=0.01)$, TBUT $(p=0.01)$, lactoferrin $(p=0.01)$ and lysozyme $(p=0.01)$ but not in TTPC $(p=0.19), H S A(p=0.74)$ and $\operatorname{sig} A(p=0.24)$ between groups. Significant correlations were noted between TBUT with lactoferrin $(r=0.02$, $p=0.02)$ and lysozyme $(r=0.63, p=0.01)$ and between MDEQ score with lactoferrin $(r=-0.34, p=0.02)$ and lysozyme $(r=-0.64, p=0.01)$. Conclusions: There are changes in specific tear protein in dry eye patients, which correlate well with clinical results. Tear protein analysis may play an important role in the diagnosis of the dry eye.

KEYWORDS: Tears, protein analysis, electrophoresis, dry eye

\section{INTRODUCTION}

The tear film is a highly specialized and carefully structured moist film that covers the cornea and conjunctiva. It contains mucins, proteins, lipids, lipoproteins, glycolipids and metabolites that lubricate, protect and provide nutrition to the cornea. ${ }^{1}$ Normal tear volume is around $6-7 \mu \mathrm{L} \mu \mathrm{L}$, and the production rate is around 1 to $1.2 \mu \mathrm{L} / \mathrm{min}$ for non stimulated (basal) tears and greater than $5 \mu \mathrm{L} / \mathrm{min}$ for stimulated (reflex) tears. ${ }^{2,3}$ Qualitatively and quantitatively; the tear composition must be maintained to ensure healthy and functional visual system. Any abnormalities affecting the constituents or the volume may disrupt the stability of the tear film and result in dry eye..$^{4,5}$

\section{Corresponding author:}

Bariah Mohd Ali, PhD

Optometry and Vision Science Program

School of Healthcare Sciences

Faculty of Health Sciences

Universiti Kebangsaan Malaysia

Jalan Raja Muda Abdul Aziz

50300 Kuala Lumpur

MALAYSIA

Tel: 603-92897495

Fax: 603-26910488

Email: bariah@medic.ukm.my
Dry eye is characterized by tear film instability and damaged exposed surface epithelium, which causes chronic irritation of the ocular surface. Flourescein tear break up time (TBUT) is the common clinical procedure used to assess tear stability. Even though this technique has been questioned for its repeatability and high variability that exist between within and in between subjects ${ }^{6,7}$ and between instruments, ${ }^{8}$ eye care practitioners have used it widely. Ethnic differences have been quoted as one of the factors that affects TBUT values. In the western population, mean TBUT value is around 15 seconds (s). ${ }^{9,10}$ Eye with value of less than $10 \mathrm{~s}$ is considered abnormal. Cho and Brown ${ }^{11}$ found that $90 \%$ of Hong Kong Chinese has TBUT values of less than $10 \mathrm{~s}$. Significant difference in TBUT values was found between different ethnic groups in Scotland, with Caucasians having the highest value. ${ }^{12}$ In Malaysia, the mean TBUT values for normal young Malays was $7.8 \pm 1.89 \mathrm{~s}$ with around $88 \%$ of the subjects having TBUT of equal or less than $10 \mathrm{~s} .{ }^{13}$

Another common variable measured to be related to ocular surface dryness is the tear's protein concentration. Versura et al. analyzed tear protein variations in patients with evaporative dry eye disease (TBUT $\leq 10$ seconds) and compared them to tears of healthy subjects (TBUT $\geq 10$ seconds). ${ }^{14}$ Their 
results showed a significant decrease in levels of lactoferrin, lipocalin-1 and lipophilinA-C in patients with evaporative dry eye disease. Yanwei et al. compared lactoferrin levels between 40 dry eye (Schirmer < 5 $\mathrm{mm}$, TBUT $<10$ seconds) and 35 normal patients (Schirmer > $5 \mathrm{~mm}$, TBUT > 10 seconds). ${ }^{15}$ Their results showed a significant decrease in lactoferrin levels in dry eye patients compared to healthy subjects. Vitali et al. found variable lactoferrin results, which were not concordant with other more diagnostic tests such as rose bengal staining, Schirmer's test and other ocular symptoms. ${ }^{6} \mathrm{Ng}$ et al. analyzed tear protein of young normal Hong Kong Chinese using Bradford and modified Lowry methods. ${ }^{16}$ Their results showed similar protein patterns with those reported values from Caucasian subjects, but the concentrations of the major proteins were not in concordance with previous reports. The authors attributed this to the large variability in the method used.

The purpose of this study was to determine the tear protein concentration of young Malays using the Bradford and Sodium Dodecyl Sulfate Polyacrylamide Gel Electrophoresis (SDS PAGE) methods. Both techniques have been widely used by previous investigators to determine the total and specific protein concentrations in tears. ${ }^{17,18}$ Some researchers suggested the use of SDS-PAGE followed by Coomassie blue staining and densitometric scanning as diagnostic tools for dry eye syndrome. ${ }^{17}$ This study investigates the total and specific protein concentrations of young Malays with dry eye symptoms and compares them with tear proteins in normal subjects. The association of tear protein concentrations with clinical findings (TBUT and MCMonnies score) will also be determined. The outcomes of this study may improve our understanding and management of dry eye patients, particularly within the Asian region.

\section{MATERIALS AND METHODS}

Subjects were recruited through advertisements on bulletin boards of Universiti Kebangsaan Malaysia (UKM), Kuala Lumpur campus. Informed consent was obtained from all subjects prior to data collection. This study was approved by the Medical Ethics Committee of UKM and followed the tenets of the declaration of Helsinki. The inclusion criteria were young Malays, who were non-contact lens wearers, refractive error of less than $\pm 3.00 \mathrm{D}$ and no history of anterior segment disease or surgery. Clinical evaluation was conducted at the Optometry Clinic and tear protein analysis was done at the Biochemistry Lab, Faculty of Health Sciences, Universiti Kebangsaan Malaysia Kuala Lumpur Campus.

All subjects were screened using the McMonnies dry eye questionnaire (MDEQ) to ascertain the number, type and frequency of dryness symptoms at the beginning of the study. ${ }^{19}$ Given the popularity of this survey among Optometrists in Asia; it is reasonable for us to use it in this study. The MDEQ was invented in 1986, and it consists of 12 questions that focus on clinical risk factors for dry eye. ${ }^{19}$ The questions employ response options that vary in number and type and provide a score from 0 to 45 . Respondents were required to answer all the 12 questions and the score of each question (which has a weighted scoring scale) was calculated. Scores above 14.5 are consistent with a dry eye. Tear stability of every subject were measured using the flourescein tear break up time (TBUT). The technique was described in an earlier report. ${ }^{20}$ The subject's upper bulbar conjunctiva was swiped with a saline wetted flourescein strip (Haag-Streit International, Switzerland). Subjects were told to close their eyes for approximately 10 seconds and then to open their eyes, blink twice and to keep the eye naturally open and look straight ahead (in primary position) with chin firmly on the chinrest of a slit lamp biomicroscope. Cobalt blue light with diffuse illumination and 10X magnification was used to determine the appearance of dark spots or streaks at the five different regions of the cornea (nasal, temporal, inferior, superior and nasal). Time from the last blink to the first appearance of random dark spots or streaks was taken as TBUT. Three consecutive readings were taken from each eye using a stopwatch, and the mean was recorded. Corneal staining was evaluated using flourescein and slit lamp biomicroscope and graded following the Efron grading scale. ${ }^{21}$ Room temperature was set between 23 to $25^{\circ} \mathrm{C}$ and room humidity level was between 45 to $50 \%$ at the time of investigation.

Tears were collected in the clinic using a sterilized glass micro-capillary tube. Around $50 \mu \mathrm{l}$ of tears was collected from each subject. The time required for collection varied between 25 and 50 minutes. After collection, the tears were stored at $-80^{\circ} \mathrm{C}$ until all subjects had completed clinical examination. The total tear protein concentration (TTPC) was determined using the Bradford Method. It is a rapid and sensitive colorimetric protein assay based on absorbance shift of the blue dye for quantitation of protein in a solution. This technique was carried out using Bio-Rad Protein assays. The assay reagent was prepared by diluting one part of reagent concentrate (Bio-Rad Laboratories, USA) with four parts of distilled water. Then, $10 \mu$ l of sample (optimized with $50 X$ dilution after a repeatability test) and $10 \mu \mathrm{l}$ of standard following serial dilution was mixed with $200 \mu \mathrm{l}$ of diluted assay reagent in a 69 micro-well plate. The absorbance of the mixture was measured at 595nm with a micro-plate reader after a least 5 minute incubation time at room temperature (Bio-Rad Technical Bulletin 1069). The obtained mean values from triplicate samples were then calculated to determine the TTPC for each tear samples.

The specific protein levels (slgA, lysozyme, lactoferrin and HSA) were determined using the Sodium Dodecyl Sulfate Polyacrylamide Gel Electrophoresis (SDS-PAGE) method. The technique was conducted on an electrophoresis system (Bio-Rad Mini-Protean Tetra Cell, Bio-Rad Laboratories, USA) 
using the Laemmli (Bio-Rad Laboratories, USA) buffer system. All non-reduced tear samples were diluted with the buffer solution in the optimized ratio of 1:4. Each $20 \mu \mathrm{l}$ of the diluted samples were then loaded into the wells on top of the stacking gel (Bio-Rad Mini Protean Pre-Cast Gels, Bio-Rad Laboratories, USA). The protein markers were also prepared by similar methods and loaded into each well. Chosen commercially available protein markers included the 66.5kDa albumin (A3782), 82.4kDa lactoferrin (L0520), 14.3kDa lysozyme (L4919) and $400-420 \mathrm{kDa}$ IgA (I1010). The protein markers were all obtained from Sigma Chemical Company, USA. Molecular weight markers (Precision Plus Protein Kaleidoscope, Bio-Rad Laboratories, USA) with 10 multicolor recombinant proteins $(10-250 \mathrm{kDa})$ were run alongside the diluted tear samples and protein markers. Electrophoresis was executed at $100 \mathrm{~V}$ for 10 minutes and subsequently, $120 \mathrm{~V}$ for 60 minutes to ensure progressive protein mobility. The generated gels were then stained with Coomassie brilliant blue dye (Nacalai Tesque CBB Stain One, Japan) for an hour. After that, the destaining process was continued overnight and dried. The final processed gels were scanned (V313, Dell, USA) using the highest resolution dots per inch (dpi) and converted into digital image. The specific protein bands were identified and quantified using image analysis. The specific protein bands from the samples were identified via the molecular weights and protein markers. Image Meter Version 1.1 for Windows (Adobe Air 3.2, USA) was used to estimate the specific protein concentrations on the gels. The areas $\left(\mathrm{mm}^{2}\right)$ of the specific protein bands were selected and compared to the protein marker's pixel by pixel.
The local background of the image was subtracted out from the analysis. The areas $\left(\mathrm{mm}^{2}\right)$ were then calculated based on the protein marker'sconcentrations to obtain the specific protein concentrations.

\section{Statistical Analysis}

Statistical analysis was performed using SPSS (Version 20.0, SPSS Inc, Chicago, IL, USA). The clinical and threshold statistical significance was taken as $\mathrm{P}$ $<0.05$. Parametric (Independent Samples T-Test) and nonparametric tests (Mann-Whitney U Test) were used to compare means between groups. Spearman test of correlation was used to find any association between variables measured.

\section{RESULTS}

A total of 42 Malay subjects ( 21 dry eye (DE) and 21 non dry eye (NDE)) aged between 19 to 31 years old participated in this study. The mean age for all subjects was $21.36 \pm 2.36$ years. Mean age for DE was $21.95 \pm 2.92$ and for NDE was $20.76 \pm 1.44$. Mean spherical refraction for DE was $-0.75 \pm 1.09 \mathrm{DS}$ and for NDE was $-1.50 \pm 2.11 \mathrm{DS}$. Mean MDEQ score for DE was $16.00 \pm 1.48$ and for NDE was $8.47 \pm 3.47$. Tear stability was evaluated using the flourescein TBUT. Mean TBUT for DE and NDE was $3.47 \pm 0.47 \mathrm{~s}$ and $4.98 \pm 0.43 \mathrm{~s}$ respectively. Evaluation of corneal health showed no significant staining in both groups. Statistical analysis indicates no significant difference $(p>0.05)$ between groups was noted in all parameters measured except for the mean MDEQ score and TBUT $(P=0.001 ; P=0.001$ respectively). Summary of results are shown in Table 1.

Table 1. Subjects demographic and clinical data

Dry eye subjects

Non dry eye subjects

Significance level (p)

\begin{tabular}{llll}
\hline Number of subjects $(\mathrm{n})$ & 21 & 21 & \\
Age (years) & $21.95 \pm 2.92$ & $20.76 \pm 1.44$ & 0.372 \\
Refractive error (DS) & $-0.75 \pm 1.09$ & $-1.50 \pm 2.11$ & 0.441 \\
Mean MDEQ score & $16.00 \pm 1.48$ & $8.47 \pm 3.47$ & $0.001^{*}$ \\
Mean TBUT (seconds) & $3.47 \pm 0.47$ & $4.98 \pm 0.43$ & $0.001^{*}$
\end{tabular}

${ }^{*} p<0.05$ is considered significant

The Bradford method was used to determine the total tear protein concentration (TTPC). Mean TTPC for a DE subject was $9.84 \pm 2.40 \mathrm{mg} / \mathrm{ml}$ and for NDE was $8.96 \pm 1.84 \mathrm{mg} / \mathrm{ml}$. No significant difference was detected between both groups $(P=0.190)$. The specific protein concentrations (slgA, lysozyme, lactoferrin and HSA) were determined using SDSPAGE technique. Mean HSA concentration for DE was $0.060 \pm 0.03 \mathrm{mg} / \mathrm{ml}$ and for NDE was $0.061 \pm 0.028 \mathrm{mg} /$ $\mathrm{ml}$. Mean lactoferrin concentrations for DE and NDE subjects were $1.469 \pm 0.248 \mathrm{mg} / \mathrm{ml}$ and $1.745 \pm 0.224 \mathrm{mg} /$ $\mathrm{ml}$ respectively. Mean lysozyme concentration for DE subjects was $1.682 \pm 0.166 \mathrm{mg} / \mathrm{ml}$ and for NDE subjects was $2.0 \mathrm{~s} 41 \pm 0.186 \mathrm{mg} / \mathrm{ml}$. Mean slgA concentrations for DE and NDE subjects were 0.543 $\pm 0.102 \mathrm{mg} / \mathrm{ml}$ was $0.569 \pm 0.089 \mathrm{mg} / \mathrm{ml}$ respectively. Statistical analysis indicates significant difference in lactoferrin $(P=0.001)$ and lysozyme $(P=0.001)$ concentrations between both groups. Results are summarized in Table 2. 
Table 2. Summary of mean tear protein concentrations dry eye and non-dry eye subjects

\begin{tabular}{llll}
\hline & Dry eye subjects & Non dry eye subjects & Significance level $(\mathrm{p})$ \\
\hline $\begin{array}{l}\text { Total tear protein } \\
\text { concentration (TTPC) }\end{array}$ & $9.84 \pm 2.40 \mathrm{mg} / \mathrm{ml}$ & $8.96 \pm 1.84 \mathrm{mg} / \mathrm{ml}$ & 0.190 \\
slgA & $0.543 \pm 0.102 \mathrm{mg} / \mathrm{ml}$ & $0.569 \pm 0.089 \mathrm{mg} / \mathrm{ml}$ & 0.237 \\
Lysozyme & $1.682 \pm 0.166 \mathrm{mg} / \mathrm{ml}$ & $2.041 \pm 0.186 \mathrm{mg} / \mathrm{ml}$ & $0.001^{*}$ \\
\hline Lactoferrin & $1.469 \pm 0.248 \mathrm{mg} / \mathrm{ml}$ & $1.745 \pm 0.224 \mathrm{mg} / \mathrm{ml}$ & $0.001^{*}$ \\
HSA & $0.060 \pm 0.03 \mathrm{mg} / \mathrm{ml}$ & $0.061 \pm 0.028 \mathrm{mg} / \mathrm{ml}$ & 0.734
\end{tabular}

${ }^{*} \mathrm{p}<0.05$ is considered significant

Correlation between MDEQ scores and TBUT values with tear protein concentrations were analyzed using Spearman's test of association. Significant correlations were noted between MDEQ scores with TTPC $(P=0.014)$, lactoferrin $(P=0.015)$ and lysozyme $(P=0.001)$ concentrations. Similar correlations were also found between TBUT with lactoferrin $(P=0.022)$ and lysozyme concentrations $(P=0.001)$.

\section{DISCUSSION}

In this study, tear protein characteristics of young Malays with dry eye symptoms were compared to normal subjects, and their associations to TBUT and MDEQ scores were determined. The McMonnies dry eye questionnaire (MDEQ) was used to elucidate the dry eye symptoms of subjects in this study. The survey has been shown to have high sensitivity and specificity for dry eye diagnosis, where a referent value of 14.5 or more denotes dry eye. ${ }^{21}$ In the present study, the scores of MDEQ between both groups were significantly different with values ranged from 14.5 to 18 for DE subjects and 5 to 13 for NDE subjects. Tear stability was determined using flourescein TBUT technique. Mean TBUT of DE subjects was significantly lower than NDE subjects with values ranged from 3 to $5 \mathrm{~s}$ and 5 to $7 \mathrm{~s}$ respectively. Result from the present study support earlier findings of TBUT in Asian population. ${ }^{11,13}$ In reports with Caucasian subjects, TBUT value of less than $10 \mathrm{~s}$ is considered as abnormal.9,10 The discrepancy was probably due to the differences in tears characteristics of Asian population. ${ }^{15}$

Detailed analysis of tear protein concentrations were conducted in this study using the Bradford and SDS-PAGE techniques, and the outcomes showed significant correlations with TBUT and MDEQ scores. However, the results showed higher TTPC than found in previous investigations. ${ }^{14,16}$ The inconsistency was probably due to the method used to collect tears. ${ }^{17,18}$ Earlier works have shown that methods of tear collection can critically affect the tear protein concentrations..$^{22} \mathrm{Ng}$ et al. postulated that stimulated tear reflex might increase the normal rate of tear secretion, thus diluting the normal tear protein concentration, rendering it to a lower value. ${ }^{16}$ However, other factors such as concentration of the Volume 12 Number 2, Dec 2013 chemical assay used, age and race of subjects may also influence the results. ${ }^{17,18}$ Results of the present study also demonstrated insignificant differences between TTPC in DE and NDE subjects. These results were in agreement with Caffery et al. who demonstrated no significant difference in TTPC between patients with keratoconjunctivitis sicca and normals in their study. ${ }^{23}$ However, their results showed significant difference in TTPC between normal and patients with Sjögren's syndrome.

The specific proteins that were analyzed in this study include HSA, lactoferrin, lysozyme and slgA. However, significant differences were only noted in lactoferrin and lysozyme concentrations between both groups. Concentrations of both proteins were found to be higher in DE than NDE groups. These findings were in accordance with several earlier investigations. ${ }^{14,24,25}$ Janssen and van Bijsterveld noted significant reduction in lactoferrin and lysozyme concentrations in the tear samples of dry eye subjects using SDS-PAGE technique. ${ }^{25}$ Versura et al. demonstrated significant decrease of lactoferrin levels in patients with evaporative dry eyes. ${ }^{14}$ Similar results were also found in patients with keratoconjunctivitis (KCS). ${ }^{23}$ It is possible that the reduction in lactoferrin and lysozyme concentrations were associated with a deficiency in the aqueous production. Around $20-40 \%$ of total protein in the tears aqueous layer is made up of lysozyme. Deficiency in the aqueous layer will result in reduction of the lysozyme concentration. According to Danjo et al., the lacrimal gland produces lactoferrin. Therefore, the function of the lacrimal gland can be evaluated by determination of level of tear lactoferrin regardless of differences in pathogenesis of underlying diseases. ${ }^{26}$

\section{CONCLUSION}

This study provides the first data on tear protein concentrations of young Malays. There are changes in specific tear protein in dry eye patients, which correlate well with clinical results. The results indicate the importance of tear protein analysis in the diagnosis of dry eye and may be used as future reference. 


\section{CONFLICTS OF INTEREST}

None declared.

\section{ACKNOWLEDGEMENT}

This research is financially supported by the UKM research grant (UKM-GUP-2011-114).

\section{REFERENCES}

1. Jacob JT, Ham B. Compositional profiling and bio marker identification of the tear film. Ocu Surf 2008; 6:175-85.

2. Mishima S, Gasset A, Klyce SD, Baum JL. Determination of tear volume and tear flow. Invest Ophthalmol 1966; 5:264-76.

3. Fullard RJ, Snyder C. Protein levels in nonstimulated and stimulated tears of normal human subjects. Invest Ophthal Vis Sci 1990; 31:1119-26.

4. King-Smith PE, Fink BA, Nichols JJ, et al. The contribution of lipid layer movement to tear film thinning and break up. Invest Ophthalmol Vis Sci 2009; 50:2747-56.

5. Bjerrum KB. Tear fluid analysis in patients with primary Sjogren's syndrome using lectin probes. Acta Ophthal Scan 1999; 77:1-8.

6. Vitali C, Moutsopoulis HM, Bombardieri S. The European Community Study Group on diagnostic criteria for Sjogren's syndrome: specificity and sensitivity of tests for ocular and oral involvement in Sjogren's syndrome. Ann Rheum Dis 1994; 53:637-47.

7. Cho P. Stability of the precorneal tear film: a review. Clin Exp Optom 1991; 74:19-25.

8. Vanley GT, Leopold IH, Gregg TH. Interpretation of tear film breakup. Arch Ophthalmol 1977; 95: 445-8.

9. Patel S, Murray, D, McKenzic, A, Shearer, DS, McGrath, BD. Effects of fluorescein on tear breakup time and on tear thinning time. Am J Optom Physiol Opt 1985; 51:765-9.

10. Kame RT, Takemura RK, Mukai GT. Tear break-up time and the Schirmer tear test. J Am Optom Assoc 1979; 47:1535-8.

11. Cho P, Brown B. Review of the TBUT technique and a closer look at the TBUT of HK-Chinese. Optom Vis Sci 1993; 70:30-8.

12. Patel S, Virhia SK, Farrell P. Stability of the pre corneal tear film in the Chinese, Africans, Indian and Caucasian eyes. Optom Vis Sci 1995; 72: 911-5.

13. Mohidin N, Amran, HR. Fluorescein tear break-up time in Malays. Jurnal Sains Kesihatan Malaysia 2004; 65-73.

14. Versura P, Nanni P, Bavelloni A, et al. Tear proteomics in evaporative dry eye disease. Eye 2010; 24:1396-402.

15. Yanwei L, Wei Z, Yu Z. The relationship between dry eye and lactoferrin levels in tears. Asian Biomedicine (Research Reviews and News) 2012; 6:81-5.
16. Ng V, Cho P, To C. Tear proteins of normal young Hong Kong Chinese. Graefes Arch Clin Exp Ophthalmol 2000; 238:738-45.

17. Coyle PK, Sibony PA, Johnson C. Electrophoresis combined with immunologic identification of human tear proteins. Invest Ophthalmol Vis Sci 1989; 30:1872-8.

18. Frey WH, DeSota-Johnson D, Hoffman C, McCall JT. Effects of stimulus on the chemical composition of human tears. Am J Ophthalmol 1981; 92:559-67.

19. McMonnies CW, Ho A. Responses to a dry eye questionnaire from a normal population. J Am Optom Assoc 1987; 58:588-91.

20. Mohd-Ali B, Leong SF, Abdul-Mutalib H, Mohidin N. Tear evaluation of subjects wearing rigid gas permeable contact lens for six months: the Asian context. Clin Ter 2011; 162:327-30.

21. Efron N. Grading scales for contact lens complications. Ophthalmic Physiol Opt 1998; 18:182-6.

22. Berta A. Collection of tear samples with or without stimulation. Am J Ophthalmol 1983; 96:115-6.

23. Caffery B, Joyce E, Boone A, et al. Tear lipocalin and lysozyme in Sjogren and non-Sjogren dry eye. Optom Vis Sci 2008; 85:661-7.

24. Janssen PT, van Bijsterveld OP. Origin and biosynthesis of human tear fluid protein. Invest Ophthalmol Vis Sci 1983; 24:623-30.

25. Stuchell RN, Farris RL, Mandel ID. Basal and reflex human tear analysis. II. Chemical analysis: lactoferrin and lysozyme. Ophthalmology 1981; 88:858-61.

26. Danjo Y, Lee M, Horimoto K, Hamano T. Ocular 12. surface damage and tear lactoferrin in dry eye syndrome. Act Ophthalmol 2009; 72:433-7. 